\title{
Repeated Cocaine Administration Attenuates Group I Metabotropic Glutamate Receptor-Mediated Glutamate Release and Behavioral Activation: A Potential Role for Homer
}

\author{
Chad J. Swanson, ${ }^{1}$ David A. Baker, ${ }^{1}$ Dan Carson, ${ }^{1}$ Paul F. Worley, ${ }^{2}$ and Peter W. Kalivas ${ }^{1}$ \\ ${ }^{1}$ Department of Physiology and Neuroscience, Medical University of South Carolina, Charleston, South Carolina 29425, \\ and ${ }^{2}$ Departments of Neuroscience and Neurology, The Johns Hopkins University of Medicine, Baltimore, Maryland \\ 21205
}

The present study aimed to characterize a functional role for group I metabotropic glutamate receptors (mGluRs) in the nucleus accumbens and the capacity of repeated cocaine to elicit long-term changes in group I mGluR function. Reverse dialysis of the group I agonist (RS)-3,5-dihydroxyphenylglycine (DHPG) into the nucleus accumbens resulted in an increase in extracellular glutamate levels that was mediated by the mGluR1 subtype and depended on voltage-dependent $\mathrm{Na}^{+}$and $\mathrm{Ca}^{2+}$ conductance. At 3 weeks after discontinuing 1 week of daily cocaine injections, the capacity of DHPG to induce glutamate release was markedly reduced. Similarly, DHPG induced an mGluR1-dependent increase in locomotor activity after microinjection into the nucleus accumbens that was significantly

Glutamate is an endogenous ligand for ionotropic glutamate receptors (iGluRs) and metabotropic GluRs (mGluRs) in the mammalian CNS. Ionotropic receptors mediate fast excitatory transmission, whereas mGluRs act via G-proteins to regulate intracellular processes, and both receptor classes have been implicated in mediating many forms of neuroplasticity (Ottersen and Landsend, 1997; Anwyl, 1999). Addiction is conceptualized as an enduring neuroplastic process resulting from repeated exposure to drugs of abuse (Wolf, 1998; Berke and Hyman, 2000; Nestler, 2001). With respect to psychostimulant drugs of abuse such as cocaine and amphetamine, addiction has been characterized as a process initiated by drug binding to monoamine transporters but involving the progressive recruitment of neuroadaptations in glutamate transmission (Wolf, 1998). However, studies to date on drug-induced neuroadaptations in glutamate transmission have focused primarily on iGluRs and glutamate release, whereas relatively little information has accrued on the role of mGluRs in this process.

The mGluRs are encoded by eight genes and have been organized into three groups according to sequence homology, pharmacological profile, and shared cell signaling mechanisms (Conn and Pin, 1997). Group I receptors (mGluR1, mGluR5) are unique in that they are positively coupled to phospholipase $\mathrm{C}$ and are

\footnotetext{
Received June 27, 2001; revised Sept. 5, 2001; accepted Aug. 31, 2001.

This work was supported by United States Public Health Service Grants MH40817, DA-03906 (P.W.K.), and DA10309 (P.F.W.) and individual National Research Service Award DA-05963-01 (C.J.S.). We thank Lindsay Windham for excellent technical assistance.

Correspondence should be addressed to Dr. Peter Kalivas, Department of Physiology and Neuroscience, Medical University of South Carolina, 173 Ashley Avenue, Room 403 BSB, Charleston, SC 29425. E-mail: kalivasp@musc.edu.

Copyright (C) 2001 Society for Neuroscience $0270-6474 / 01 / 219043-10 \$ 15.00 / 0$
}

blunted 3 weeks after repeated cocaine administration. Signaling through group I mGluRs is regulated, in part, by Homer proteins, and it was found that the blunting of group I mGluRinduced glutamate release and motor activity after repeated cocaine was associated with a reduction in Homer $1 \mathrm{~b} / \mathrm{c}$ protein that was selective for the medial nucleus accumbens. These data show that repeated cocaine produces an enduring inhibition of the neurochemical and behavioral consequences of stimulating mGluR1 that is accompanied by changes in the mGluR scaffolding apparatus.

Key words: mGluR; cocaine; Homer; nucleus accumbens; glutamate; locomotion; microdialysis associated with the Homer (Vesl) family of intracellular proteins (Brakeman et al., 1997; Kato et al., 1998; Xiao et al., 1998). The three products encoded by the Homer1 gene have been examined in greatest detail and act as intracellular scaffolding proteins to regulate mGluR signaling ( $\mathrm{Tu}$ et al., 1999). Homer1b/c proteins are constitutively expressed proteins that functionally link mGluR1 and mGluR5 with the $\mathrm{IP}_{3}$ receptor on the endoplasmic reticulum, as well as connect mGluR1 and mGluR5 with iGluRs by binding other scaffolding proteins (Naisbitt et al., 1999; Tu et al., 1999). In contrast, Homer1a has low constitutive expression but displays robust increased synthesis in response to augmented synaptic activity.

Group I mGluRs are present in high density within the nucleus accumbens (Romano et al., 1995), a brain region known to be important in psychostimulant-induced behavioral neuroplasticity (Nestler, 2001). The nucleus accumbens receives dopaminergic innervation from the ventral mesencephalon (Fallon and Moore, 1978) and glutamatergic afferents primarily from cortical and allocortical brain regions (Meredith et al., 1993). Psychostimulant-induced neuroadaptations in both dopamine and glutamate transmission in the nucleus accumbens have been documented, including enduring changes in transmitter release and postsynaptic signaling (Pierce and Kalivas, 1997; Wolf, 1998). However, although some behavioral evidence exists for the involvement of mGluRs in amphetamine-induced locomotion (Kim and Vezina, 1998), no studies to date have provided direct evidence for enduring psychostimulant-induced neuroadaptations in mGluR1 and mGluR5 neurotransmission.

The present study examines the capacity of repeated cocaine administration to produce enduring changes in mGluR1 and mGluR5 neurotransmission in the nucleus accumbens. The effect 
of repeated cocaine administration on the physiology and pharmacology of mGluR1 and mGluR5 responses was examined by combining in vivo microdialysis, mGluR-mediated behavioral activation, and immunoblotting. Taken together, these experiments indicate that repeated cocaine administration blunts the functional consequence of stimulating mGluR1 and mGluR5, and they pose a possible role for reduced expression of Homer1b/c.

\section{MATERIALS AND METHODS}

Animals and surgery. Male Sprague Dawley rats (Harlan, Indianapolis, IN) (Western blot studies, all behavioral studies, and microdialysis studies involving cocaine administration) or male Charles River rats (Raleigh, NC; microdialysis studies without cocaine administration) weighing between 275 and 300 gm were housed individually in an ALAC-approved animal facility with food and water available ad libitum. Rooms were set on a $12 \mathrm{hr}$ light/dark cycle (7:00 A.M./7:00 P.M.) to regulate the animal photocycle, and all experimentation was conducted during the light period. Surgeries were performed $7 \mathrm{~d}$ after arrival of the subjects, and experiments were begun 1 week after the surgical procedure. Animals were anesthetized with a combination of ketamine (100 $\mathrm{mg} / \mathrm{kg}$, i.m.) and xylazine ( $3 \mathrm{mg} / \mathrm{kg}$, i.m.). Microinjection studies used indwelling guide cannulas ( 26 gauge, $14 \mathrm{~mm}$; Small Parts, Roanoke, VA) implanted $1 \mathrm{~mm}$ above the infusion site in the nucleus accumbens $[+1.2$ $\mathrm{mm}$ anterior to bregma, $\pm 1.5 \mathrm{~mm}$ mediolateral, $-6.5 \mathrm{~mm}$ ventral to the skull surface according to the atlas of Paxinos and Watson (1986)]. The nucleus accumbens stereotaxic coordinates were chosen to place dialysis probes and injection cannulas at the interface between the shell and core compartments (Heimer et al., 1991). Functional differences between the shell and core with regard to enduring neuroadaptations produced by psychostimulants have been observed (Pierce et al., 1996; Cadoni and Di Chiara, 1999). By placing cannulas at the shell/core interface it was reasoned that we could observe enduring changes evoked by repeated cocaine that may be selective for either accumbens compartment. The guide cannulas were fixed to the skull with three stainless steel skull screws (Small Parts) and dental acrylic. The guide cannulas were fitted with obturators ( 33 gauge, $14 \mathrm{~mm}$; Small Parts) between testing periods to prevent blockade by debris. The stereotaxic implantation of microdialysis cannulas was conducted as described above except that the coordinates were changed to $+1.1 \mathrm{~mm}$ anterior to bregma, $\pm 2.5 \mathrm{~mm}$ mediolateral, $-4.7 \mathrm{~mm}$ dorsoventral (from skull) with the cannulas (20 gauge; $14 \mathrm{~mm}$ ). The dialysis cannulas were angled at $6^{\circ}$ from vertical to place the active dialysis membrane at approximately $\pm 1.5 \mathrm{~mm}$ mediolateral to the midline in the nucleus accumbens, just medial to the anterior commissure.

Drugs and repeated cocaine treatment. Cocaine was generously donated by the National Institute of Drug Abuse, and all drugs in this study were purchased from Tocris Cookson (Ballwin, MO). Cocaine, $(S)$-3,5-dihydroxyphenylglycine (behavioral experiments) and (RS)-3,5-dihydroxyphenylglycine (DHPG; microdialysis experiments) and 6-nitro-7sulfamoylbenzo[f]quinoxaline-2,3dione disodium (NBQX, disodium salt) were dissolved in $0.9 \%$ sterile saline. Vehicle injections for these drugs consisted of sterile $0.9 \%$ saline. (RS)-2-Chloro-5-hydroxyphenylglycine (CHPG) was dissolved in 1.1 equivalents $\mathrm{NaOH}$ (Sigma, St. Louis, MO), neutralized with $0.1 \mathrm{~N} \mathrm{HCl}$ (Sigma), and diluted with sterile water. The vehicle injections for CHPG consisted of neutralized $\mathrm{NaOH} / \mathrm{HCl}$ solution. 2-Methyl-6-(phenylethynyl)pyridine (MPEP) was dissolved in sterile water and diluted with $0.9 \%$ saline. Vehicle injections for MPEP experiments consisted of an equivalent volume of sterile water diluted with sterile $0.9 \%$ saline. For the dialysis experiments, compounds were initially dissolved as outlined above and diluted with filtered dialysis buffer (see below). Tetrodotoxin (TTX) and $\omega$-conotoxin GVIA were dissolved directly into dialysis buffer. In addition, $(R, S)$-1-aminoindan1,5-dicarboxylic acid (AIDA) was dissolved in 1.1 equivalents. $\mathrm{NaOH}$, neutralized with $0.1 \mathrm{~N} \mathrm{HCl}$, and diluted with filtered dialysis buffer. Cocaine was dissolved the day of the experiment, and all other drugs were made up in bulk, aliquoted, and stored at $-80^{\circ} \mathrm{C}$ for later use. All doses for intracranially administered drugs are expressed as total brain dose (e.g., $5 \mathrm{nmol}=2.5 \mathrm{nmol} / 0.5 \mu \mathrm{l}$ per side).

In all experiments that included repeated administration of cocaine, animals were assigned to saline or cocaine treatment groups 1 week after arrival in the animal facility. Behavioral activity was monitored in an infrared photocell chamber (see below for details). All rats were adapted to the photocell boxes $24 \mathrm{hr}$ before experimentation by placing them in the chambers for $60 \mathrm{~min}$, giving them sham intraperitoneal injections, and returning them to the cages for $2 \mathrm{hr}$. After behavioral measurements were made, the rats were returned to their home cages. On the first day of the repeated administration regimen, rats received either saline or cocaine $(15 \mathrm{mg} / \mathrm{kg}$, i.p.) just before behavioral testing. On days 2 through 6 , the rats received either saline or cocaine $(30 \mathrm{mg} / \mathrm{kg}$, i.p.) in their home cages, and motor behavior was not evaluated during this period. Motor activity was again monitored on day 7 while the animals received either saline or cocaine $(15 \mathrm{mg} / \mathrm{kg}$, i.p.). This cocaine injection regimen has previously been shown to elicit behavioral sensitization and enduring alterations in dopamine and glutamate transmission (Pierce and Kalivas, 1997). The lower dose of cocaine was used on days of behavioral testing because this dose is shown to produce motor activation with little stereotyped behavior (Kalivas et al., 1988). Behavioral analyses were conducted on days 1 and 7 to determine whether animals developed early behavioral sensitization to the repeated injections of saline and cocaine. Results from the Western blot and behavioral experiments were pooled, and early behavioral sensitization was determined by comparing day 7 horizontal photocell counts with day 1 activity for subjects receiving repeated saline or cocaine. A one-way ANOVA with repeated measures over treatment day indicated that animals given repeated cocaine injections showed significantly higher motor activity on day 7 when compared with day 1 of treatment $(n=28$; day $1=28815 \pm 2935$, day $7=38860 \pm$ 2152 mean \pm SEM total photocell counts over 120 min test period; $\left.F_{(1,44)}=7.614 ; p=0.008\right)$. In contrast, subjects receiving saline treatments did not show a sensitized response between days 1 and $7(n=24$; day $1=6847 \pm 467$, day $\left.7=5971 \pm 681 ; F_{(1,40)}=1.125 ; p=0.295\right)$. Motor activity data were not recorded for the microdialysis experiments.

Photocell apparatus and microinjection. Motor activity was monitored in clear Plexiglas boxes measuring $41 \times 41 \times 30 \mathrm{~cm}$ (Omnitech Instruments, Columbus, OH). A series of 16 photocell beams ( 8 on each horizontal axis) tabulated horizontal counts, and a series of 8 beams located $8 \mathrm{~cm}$ above the floor spanned each box to estimate vertical activity (rearing). Total photocell beam breaks (horizontal activity), distance traveled (an estimation of locomotor activity expressed in centimeters), vertical activity (an estimate of rearing), and estimated stereotypy (repeated breaking of the same photocell beam) were recorded by computer and stored for each test day. Each trial consisted of a $1 \mathrm{hr}$ habituation period during which animals were placed in photocell boxes before microinfusion or intraperitoneal treatments. After intraperitoneal injections or drug microinfusion, motor activity was monitored every $15 \mathrm{~min}$ for $2 \mathrm{hr}$. Animals were returned to their home cages after the $2 \mathrm{hr}$ test period and received a maximum of five such trials separated by a minimum $2 \mathrm{~d}$ intertrial interval. A counterbalanced design across days over the entire testing period was used to eliminate order effects of drug infusion.

Immediately before testing, the obturators were removed, and the injection cannulas (33 gauge, $15 \mathrm{~mm}$; Plastics One) were attached to a 1 $\mu \mathrm{l}$ Hamilton syringe via PE-20 tubing. Injection cannulas were inserted to a depth $1 \mathrm{~mm}$ below the guide cannulas. Bilateral infusions were performed over $60 \mathrm{sec}$ in a volume of $0.5 \mu \mathrm{l}$ per side. The inf usion pump was turned off, and injectors were left in place for an additional $60 \mathrm{sec}$ to prevent back-flow of infused drug. At this time the obturators were replaced, and the animals were immediately returned to the photocell cages to measure motor activity.

In vivo microdialysis. For those studies involving cocaine administration, microdialysis was conducted at either 1 or $21 \mathrm{~d}$ after the last daily injection of cocaine or saline. The night before the experiment, microdialysis probes (with $\sim 1.5 \mathrm{~mm}$ active membrane) were placed through the guide cannula into the nucleus accumbens. The following day, dialysis buffer containing (in $\mathrm{mM}$ ): $5 \mathrm{KCl}, 140 \mathrm{NaCl}, 1.4 \mathrm{CaCl}_{2}, 1.2 \mathrm{MgCl}_{2}$, 5.0 glucose, plus $0.2 \mathrm{PBS}$ to give a $\mathrm{pH}$ of 7.4 , was advanced through the probe at a rate of $2.0 \mu \mathrm{l} / \mathrm{min}$ via syringe pump (Bioanalytical Systems, West Lafayette, IN) for $120 \mathrm{~min}$. Baseline samples were collected for 100 min, and then drugs were administered through the probe for $60 \mathrm{~min}$ per dose. Throughout the experiment, samples were taken every $20 \mathrm{~min}$. In each experiment, multiple doses of DHPG were administered alone or in combination with other drugs including the mGluR1 antagonist AIDA $(300 \mu \mathrm{M})$, the mGluR5 antagonist MPEP $(10 \mu \mathrm{M})$, the N-type $\mathrm{Ca}^{2+}$ channel blocker $\omega$-conotoxin GVIA $(10 \mu \mathrm{M})$, or the voltage-dependent $\mathrm{Na}^{+}$channel blocker TTX $(1 \mu \mathrm{M})$. Doses of antagonists were chosen on the basis of effective doses in previous microdialysis studies (Pierce et al., 1996) and the relative $\mathrm{IC}_{50}$ values for inhibiting binding to the respective receptors $(\mathrm{AIDA}=7-300 \mu \mathrm{M}$ at mGluR1; MPEP $=36 \mathrm{nM}$ at mGluR5) (Pin et al., 1999). 
Quantification of glutamate. The concentration of glutamate was determined using HPLC with fluorometric detection. The dialysis samples were collected into $10 \mu \mathrm{l}$ of $0.05 \mathrm{M} \mathrm{HCl}$ containing $2.0 \mathrm{pmol}$ of homoserine as an internal standard. The mobile phase has been described previously (Moghaddam, 1993). A reversed-phase column $(10 \mathrm{~cm}, 3 \mu \mathrm{m}$ ODS; Bioanalytical Systems) was used to separate amino acids, and precolumn derivatization of amino acids with $O$-phthalaldehyde was performed using an autosampler (Gilson Medical Supplies, Middleton, WI). Glutamate was detected by a fluorescence spectrophotometer (Shimadzu, Columbia, MD) using an excitation wavelength of $300 \mathrm{~nm}$ and an emission wavelength of $400 \mathrm{~nm}$. Peak heights were measured, normalized to the internal standard homoserine, and compared with an external standard curve for quantification. The limit of detection for glutamate (three times above background) was 1-2 pmol.

Immunoblotting. Three weeks after the last daily injection of saline or cocaine, the rats were decapitated, and the brains were rapidly removed and grossly dissected into coronal sections on ice. The appropriate brain regions, including the prefrontal cortex, ventral tegmental area, dorsolateral striatum, medial nucleus accumbens (including the shell and medial core) (Heimer et al., 1991), and lateral nucleus accumbens (including only the core), were sampled on an ice-cooled Plexiglas plate using a 15 gauge tissue punch. Brains were quickly frozen at $-80^{\circ} \mathrm{C}$ until homogenized.

The dissected brain punches were homogenized with a handheld tissue grinder in homogenization medium $(0.32 \mathrm{M}$ sucrose, $2 \mathrm{~mm}$ EDTA, $1 \%$ SDS, $50 \mu \mathrm{M}$ phenylmethylsulfonyl fluoride, $1 \mu \mathrm{g} / \mathrm{ml}$ leupeptin; $\mathrm{pH}$ 7.2), subjected to low-speed centrifugation $(2000 \times g$, to remove insoluble material), and frozen at $-80^{\circ} \mathrm{C}$. Protein determinations were performed using the Bio-Rad Dc protein assay (Bio-Rad, Hercules, CA) according to the manufacturer's instructions. Samples $(15 \mu \mathrm{g})$ were subjected to SDS-PAGE using a minigel apparatus (Bio-Rad; $6 \%$ for mGluR1 and mGluR5 and $10 \%$ for Homer1b/c), transferred via semidry apparatus (Bio-Rad) to nitrocellulose membrane, and probed for the proteins of interest (one gel per protein per brain region). mGluR1a and mGluR5 were labeled using rabbit anti-rat antibodies purchased from Upstate Biotechnology (Lake Placid, NY) reactive to a peptide sequence targeted on the $\mathrm{C}$ terminus at dilutions of 1:40,000 and 1:1000, respectively. Homer $1 \mathrm{~b} / \mathrm{c}$ was probed with a rabbit anti-rat antibody (Dr. Paul Worley, Johns Hopkins University) also targeted at the $\mathrm{C}$ terminus of the protein (1:1000 dilution). Labeled proteins were detected using an HRPconjugated anti-rabbit secondary IgG diluted 1:40,000 (mGluR5) and 1:12,000 (mGluR1 and Homer1bc; Upstate Biotechnology) and visualized with enhanced chemoluminescence (Amersham Life Sciences, Arlington Heights, IL). Assurance of even transfer of protein was evaluated with Ponceau 5 (Sigma) followed by destaining with deionized water. Immunoreactivity levels were quantified by integrating band density $\times$ area using computer-assisted densitometry (NIH Image 1.60). Brain samples were linear from 5 to $80 \mu \mathrm{g}$ for all regions tested. The density $\times$ area measurements were averaged over three control samples for each gel, and all bands were normalized as percentage of control values.

Histology and statistical analysis. After experimentation, rats were administered an overdose of pentobarbitol (>100 mg/kg, i.p.) and transcardially perfused with $0.9 \%$ saline followed by $10 \%$ formalin solution. Brains were removed and placed in $10 \%$ formalin for at least 1 week to ensure proper fixation. The tissue was blocked, and coronal sections (100 $\mu \mathrm{m})$ were made through the site of injection or dialysis with a vibratome. The brains were then stained with cresyl violet to verify anatomical placement, which was completed by an individual unaware of the behavioral response of the animal.

The StatView statistics package was used to evaluate statistical significance. Behavioral sensitization was estimated using a one-way ANOVA with repeated measures over treatment day comparing days 1 and 7 within each pretreatment group. Behavioral and microdialysis experiments involving repeated cocaine treatments were analyzed using a two-way ANOVA with repeated measures over time. After discovery of statistical significance, post hoc comparisons were made with a Fischer's PLSD. Behavioral experiments performed to elucidate the pharmacological basis of DHPG action used a two-way ANOVA repeatedmeasures analysis with repeated measures over time, whereas microdialysis studies used a one-way repeated-measures ANOVA over dose. Again, the Fischer's PLSD was used in post hoc comparisons for dose of each drug. Western blot data were analyzed using a one-way ANOVA.

\section{RESULTS \\ DHPG-mediated glutamate release is impulse dependent and mediated via an mGluR1-selective mechanism}

In vivo microdialysis was performed in the nucleus accumbens to evaluate the capacity of DHPG to elicit an increase in extracellular glutamate levels. Figure $1 A$ illustrates that reverse dialysis of DHPG into nucleus accumbens results in an elevation in extracellular glutamate levels in drug-naïve animals. Figure $1 B$ shows that the increase in extracellular glutamate produced by $50 \mu \mathrm{M}$ DHPG was reversible because removal of DHPG from the dialysis buffer resulted in a return of glutamate to baseline values. Extracellular levels of glutamate are derived from both neuronal and glial sources (Timmerman and Westerink, 1997), and Figure $1 C$ reveals that the DHPG-mediated rise in extracellular glutamate was blocked by the voltage-dependent $\mathrm{Na}^{+}$channel blocker TTX (1 $\mu \mathrm{M})$, suggesting that the DHPG-induced increase in extracellular glutamate is dependent on neuronal activity. Akin to previous studies (Timmerman and Westerink, 1997), perfusion of TTX alone $(1 \mu \mathrm{M})$ did not significantly alter basal extracellular glutamate levels. The elevation in extracellular glutamate produced by DHPG was also inhibited by blocking $\mathrm{N}$-type $\mathrm{Ca}^{2+}$ channels with $\omega$-conotoxin GVIA (Fig. 1D), supporting a role for vesicular release from presynaptic terminals. DHPG has nearly equal affinity for both group I mGluR subtypes (i.e., mGluR1 and mGluR5) (Pin et al., 1999), and selective antagonists to group I mGluR subtypes were coadministered with DHPG to elucidate the relative contribution of these receptors to DHPG-induced glutamate release. Figure $1, E$ and $F$, illustrate that DHPGinduced elevation in extracellular glutamate was blocked by the selective mGluR1 antagonist AIDA $(300 \mu \mathrm{M})$ but not by the mGluR5-selective antagonist MPEP $(10 \mu \mathrm{M})$, respectively. These data indicate a role for mGluR stimulation in DHPG-induced glutamate release. Figure $1 G$ summarizes the data as percentage of baseline glutamate levels for each drug tested and shows a significant increase in glutamate after $50 \mu \mathrm{M}$ dialysis of DHPG in the DHPG alone (Fig. $1 A, B$ ) or the DHPG plus MPEP groups (Fig. 1F).

\section{Group I mGluR-mediated increase in extracellular glutamate is blunted by repeated cocaine administration}

Figure 2 illustrates that the stimulation of group I mGluRs by reverse dialysis of DHPG induced an increase in extracellular glutamate levels in animals pretreated 3 weeks earlier with daily injections of saline. Both doses of DHPG (5 and $50 \mu \mathrm{M})$ elicited a significant elevation in extracellular glutamate levels when compared with baseline. In contrast, animals pretreated 3 weeks earlier with daily cocaine injections showed no significant elevation in extracellular glutamate levels in response to DHPG when compared with baseline values over the dose range tested. Comparison between saline- and cocaine-treated animals revealed a significant blunting of the increase in extracellular glutamate in cocainetreated animals at both the 5 and $50 \mu \mathrm{M}$ concentrations of DHPG.

\section{DHPG-induced motor activation is dependent on mGluR1-mediated glutamate release and AMPA receptor stimulation}

It was demonstrated previously that DHPG microinjection into the nucleus accumbens elicits a dose-dependent increase in motor activity that is abolished by coadministration with the selective mGluR1 antagonist 7-(hydroxyamino)cyclopropa[b]chromen-1a- 

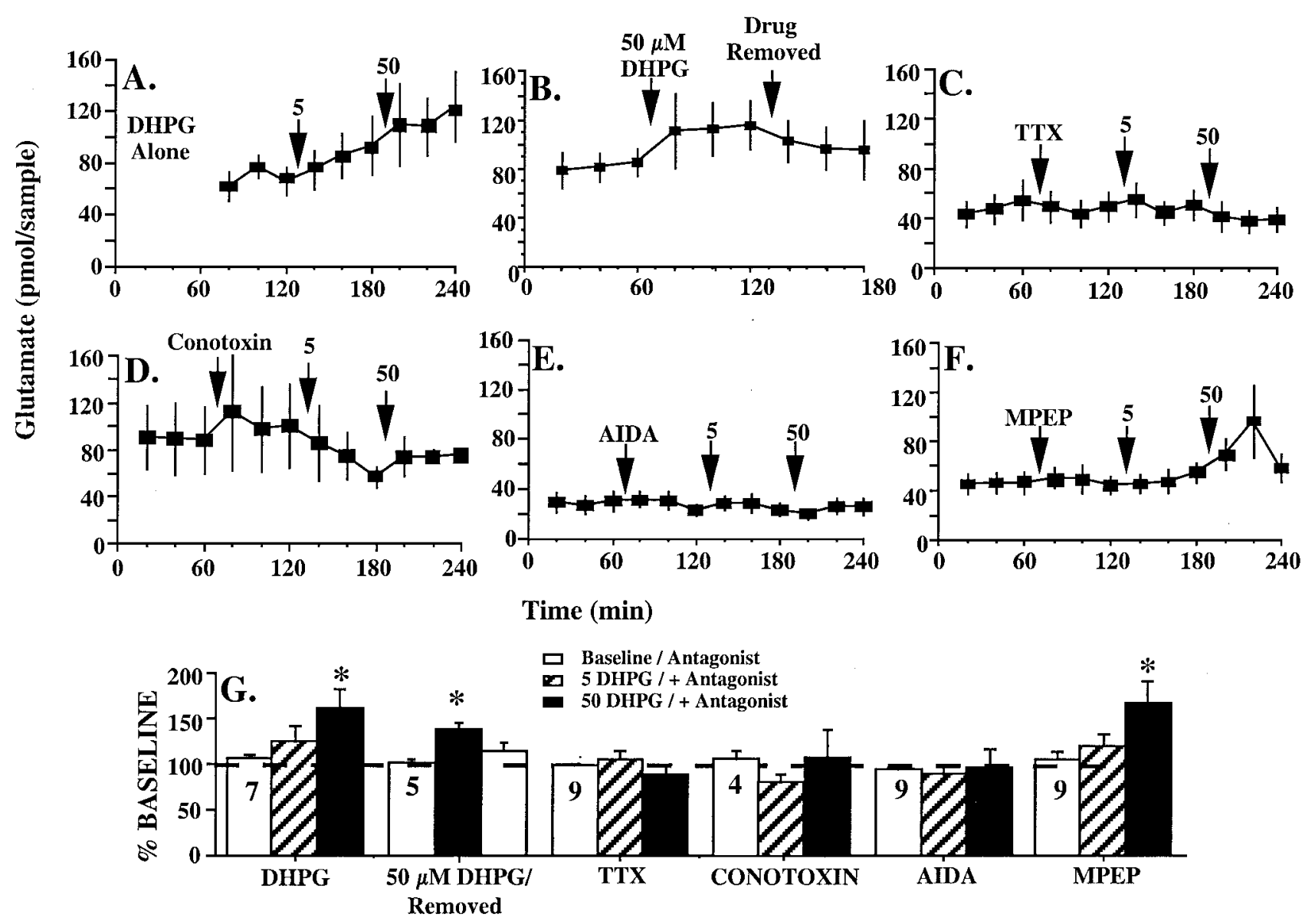

TREATMENT

Figure 1. DHPG-induced elevation in extracellular glutamate levels in nucleus accumbens is activity and mGluR1 dependent. Data are represented as picomoles of glutamate per sample in $A-F$ and normalized as percentage of baseline glutamate levels in $G$. Raw data represent three 20 min samples collected for each treatment (new treatment introduced at arrows), including buffer, $5 \mu \mathrm{M}$ DHPG, $50 \mu \mathrm{M}$ DHPG $(A)$; buffer, $50 \mu \mathrm{M}$ DHPG, buffer $(B)$; and buffer, antagonist alone, $5 \mu \mathrm{M}$ DHPG plus antagonist, and $50 \mu \mathrm{M}$ DHPG plus antagonist $(C-F)$. Percentage control data were generated comparing the mean of the last two treatment values for an animal to the mean of three of its own baseline values. $A$, Reverse dialysis of DHPG resulted in an increase in extracellular glutamate levels. $B$, Reverse dialysis of $50 \mu \mathrm{M}$ DHPG significantly elevated extracellular glutamate levels when administered for $1 \mathrm{hr}$ without previous exposure to the lower DHPG dose $(5 \mu \mathrm{M})$, and glutamate levels dropped to baseline levels after removal of the drug from the dialysis buffer. $C$, The voltage-gated $\mathrm{Na}^{+}$channel blocker TTX $(1 \mu \mathrm{M})$ prevented the ability of either dose of DHPG to increase extracellular glutamate levels. $D$, The N-type voltage-gated $\mathrm{Ca}^{2+}$ channel blocker conotoxin GVIA prevented the ability of both 5 and $50 \mu \mathrm{M}$ DHPG to significantly elevate extracellular glutamate levels. $E$, Coadministration of the mGluR1-selective antagonist AIDA $(300 \mu \mathrm{M})$ with DHPG completely abolished the ability of DHPG to increase extracellular glutamate levels over the entire dose range tested. $F$, DHPG reverse dialysis elevated extracellular glutamate levels in the presence of the potent mGluR5-selective antagonist MPEP $(10 \mu \mathrm{M})$. $G$, The percentage baseline data were derived from each of the separate experimental groups outlined in $A-F$, comparing dose of DHPG or DHPG + antagonist in each experimental group with their own baseline glutamate levels. A one-way ANOVA with repeated measures over DHPG dose for each respective experimental group revealed significant effects in animals administered DHPG alone [ $\left.(A) F_{(2,12)}=5.223 ; p=0.0234\right], 50 \mu \mathrm{M}$ DHPG only $\left[(B) F_{(2,14)}=8.683 ; p=0.0099\right]$ or DHPG plus the mGluR5-selective antagonist MPEP $\left(F_{(3,24)}=4.517 ; p=0.012\right)$ with post hoc comparisons revealing a significant effect at the $50 \mu \mathrm{M}$ dose of DHPG when compared with baseline glutamate levels using Fischer's PLSD. There was no significant effect of treatment in experiments using DHPG plus TTX, conotoxin, or AIDA comparing glutamate levels at each DHPG dose with baseline glutamate levels for each group. The number of determinations for each experimental group is shown in $G .{ }^{*} p<0.05$, comparing baseline with $50 \mu \mathrm{M}$ DHPG alone or $50 \mu \mathrm{M}$ DHPG plus MPEP.

carboxylate ethyl ester (CPCCOEt) (Swanson and Kalivas, 2000). In support of a selective action of DHPG on mGluR1, Figure $3 A$ shows that DHPG-induced motor activity was not blocked by the mGluR5 selective antagonist MPEP (0.1 or $1.0 \mathrm{nmol}$ ). Furthermore, Figure $3 B$ shows that microinjection of the mGluR5 selective agonist CHPG did not elicit an increase in motor activity over the entire dose range tested $(3,10,30 \mathrm{nmol})$.

Given the fact that the mGluR1 subtype mediates both DHPGstimulated glutamate release and behavioral activation, it is possible that the agonist-induced increase in extracellular glutamate levels may contribute to the behavioral activation observed after microinjection of DHPG into nucleus accumbens. Consistent with a role for DHPG-mediated glutamate release in behavioral activation, Figure $3 C$ demonstrates the ability of the AMPA receptor antagonist NBQX to block DHPG-induced motor activity. Figure $3 D$ shows that this blockade was over the entire time course of the DHPG effect.

\section{DHPG-induced motor activation is blunted after repeated cocaine administration}

Figure $4 A$ illustrates that after 3 weeks of withdrawal from repeated cocaine administration the capacity of DHPG microin- 

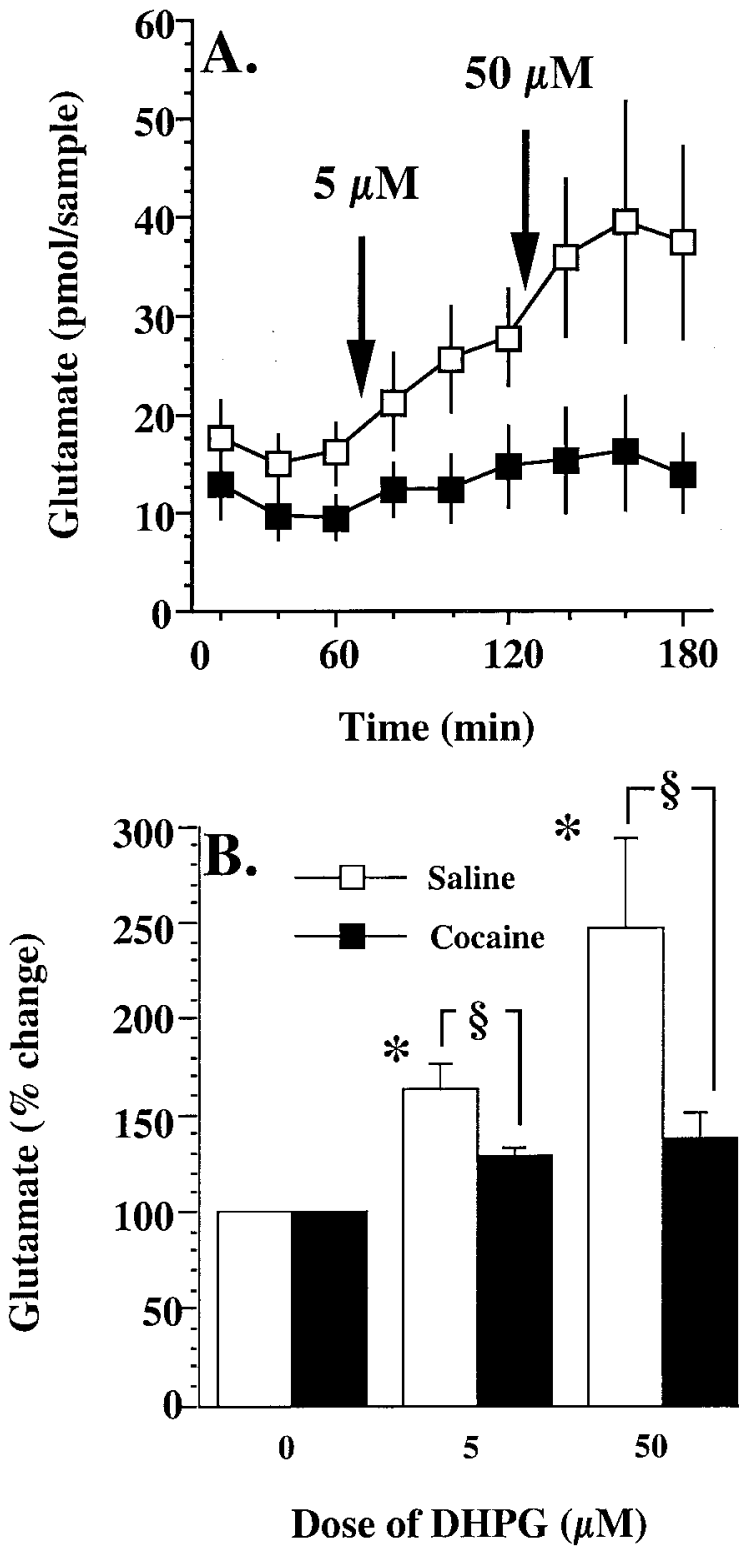

Figure 2. Three week withdrawal from repeated cocaine administration blunts DHPG-mediated increase in extracellular glutamate in the nucleus accumbens. Data are represented as picomoles per sample in $A$ and expressed as percentage of baseline glutamate levels \pm SEM in $B$. The percentage change data in $B$ represent the average of the last two samples collected at each dose of DHPG. The number of determinations in each pretreatment group was as follows: repeated saline $=7$; repeated cocaine $=7$. Two-way ANOVA with repeated measures over dose reveals significant effects of pretreatment $\left(F_{(1,12)}=5.806 ; p=0.0329\right)$ and dose of $\operatorname{DHPG}\left(F_{(2,24)}=12.796 ; p=0.0002\right)$ with respect to increased extracellular glutamate levels. There was also a significant pretreatment $\times$ dose interaction $\left(F_{(2,24)}=3.774 ; p=0.0376\right)$. Post hoc analysis with Fischer's PLSD reveals that animals pretreated with cocaine and withdrawn for 3 weeks displayed significantly lower extracellular glutamate levels at 5 and $50 \mu \mathrm{M}$ DHPG when compared with saline-pretreated controls. Subjects administered repeated cocaine showed no significant elevation in extracellular glutamate levels over the entire dose range tested. ${ }^{*} p<0.05$, comparing saline and cocaine pretreatment within each dose of DHGP tested. ${ }^{\S} p<0.05$, comparing saline pretreatment with cocaine pretreatment within each dose of DHPG.

jection into the nucleus accumbens to increase horizontal photocell counts was blunted compared with animals pretreated with daily saline injections. Figure $4 B$ shows that the reduction of horizontal photocell counts was accompanied by a significant decrease in distance traveled (an estimate of locomotion). Figure 4, $C$ and $D$, reveals that neither vertical activity nor stereotyped behavior was significantly different between saline- and cocainepretreated animals at any dose tested. Thus, the blunting in behavioral activation observed in animals given cocaine pretreatment appears to be caused primarily by a decrease in general locomotor activity and is not the result of an increase in stereotyped behavior associated with previous cocaine exposure. The time course data in Figure $4 E$ shows a general attenuation of DHPG-induced horizontal photocell counts over the entire $2 \mathrm{hr}$ test period in animals pretreated with repeated cocaine injections compared with control subjects.

\section{Withdrawal from repeated cocaine administration alters group I mGluR and Homer1 gene products selectively in the medial nucleus accumbens}

The levels of mGluR1a, mGluR5, and Homer1b/c proteins were measured at 3 weeks after discontinuing daily cocaine administration. Figure $5 A$ illustrates representative immunoblots of each protein in the medial nucleus accumbens. Figure $5 B$ reveals that a significant reduction in mGluR5 and Homer1b/c protein levels was observed in the medial nucleus accumbens of animals withdrawn from repeated cocaine administration. Table 1 shows that withdrawal from repeated cocaine treatment was without effect on the levels of mGluR1, mGluR5, or Homer1b/c in any other brain region tested, including the lateral nucleus accumbens, the prefrontal cortex, the ventral tegmental area, and the dorsolateral striatum.

\section{DHPG-induced glutamate release and Homer1bc levels are unaltered in the medial nucleus accumbens at 24 hr after the last daily cocaine injection}

A number of the enduring neuroadaptations produced by repeated cocaine administration are reduced or absent during the first 1-3 d after discontinuing daily drug injection. These alterations are measurable only after a more extended withdrawal period and include changes in extracellular dopamine and glutamate in the nucleus accumbens (Kalivas and Duffy, 1993; Paulson and Robinson, 1995; Heidbreder et al., 1996; Pierce et al., 1996; Wolf et al., 1998). Figure 6 shows that $1 \mathrm{~d}$ after the last daily injection of cocaine the group I mGluR-related neuroadaptations were not present. The capacity of DHPG to elevate extracellular glutamate was similar between the daily cocaine and saline groups (Fig. 6A,B). Likewise, no difference in protein levels of mGluR 5 or Homer $1 \mathrm{~b} / \mathrm{c}$ was observed at $1 \mathrm{~d}$ after the last injection of saline or cocaine $(\mathrm{mGluR5}-$ saline $=100 \pm 1, n=8$, cocaine $=$ $107 \pm 3, n=15 ;$ Homer1b/c-saline $=100 \pm 5, n=8$, cocaine $=$ $95 \pm 2, n=16$ ). These data reveal that at a withdrawal time at which repeated cocaine does not alter the levels of Homer1b/c, cocaine also does not change the capacity of mGluR1 and mGluR5 stimulation to elevate extracellular glutamate.

\section{Histology}

Figure $7 A$ depicts the location of the ventral tip of the injection cannulas for the behavioral experiments. The cannulas were distributed throughout the medial nucleus accumbens in both the shell and medial core regions. Figure $7 B$ depicts the dialysis probe placements in the nucleus accumbens. The probes were located in both the shell and medial core regions of the nucleus accumbens. Note that portions of the active membrane from some probes extended from the dorsal core into the ventral striatum or ventral to the shell into the diagonal band of Broca. 

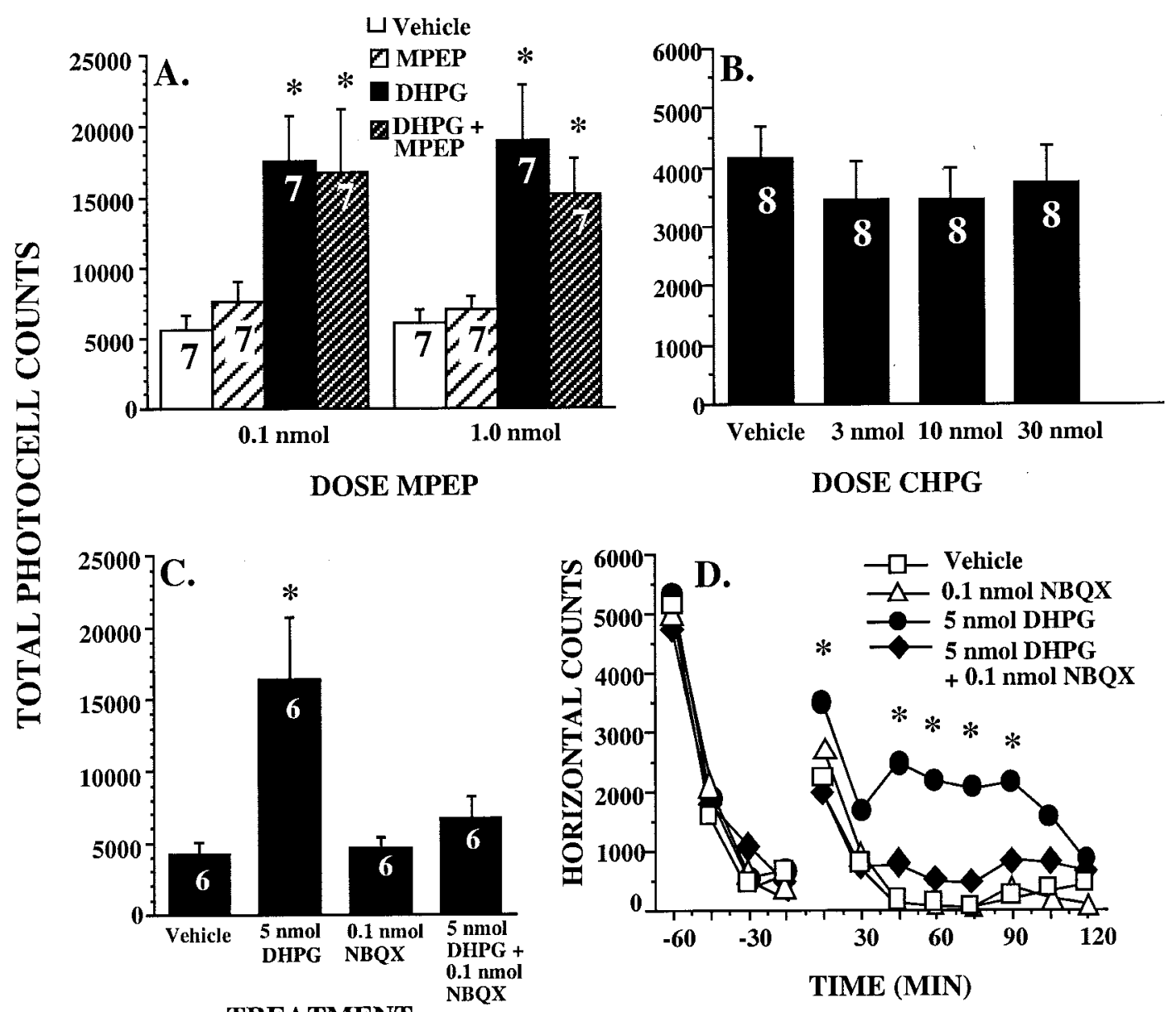

Figure 3. DHPG does not produce motor activation via mGluR5 stimulation, and motor stimulation is blocked by an AMPA receptor antagonist. Data are represented as mean \pm SEM total photocell counts during the $2 \mathrm{hr}$ after microinjection. $A$, Results of two separate experiments in which the mGluR5 selective antagonist, MPEP, was used in an attempt to block DHPG-induced motor activity. MPEP was unable to block motor activity elicited by DHPG microinjection into nucleus accumbens at either the 0.1 or $1.0 \mathrm{nmol}$ doses. A two-way ANOVA with repeated measures over time shows significant treatment effects for the $0.1 \mathrm{nmol}\left(F_{(3,24)}=4.457 ; p=0.0126\right)$ and $1.0 \mathrm{nmol}\left(F_{(3,24)}=6.542 ; p=0.0022\right)$ MPEP experiments. $B$, The mGluR5 selective agonist CHPG did not produce behavioral activation when microinjected into nucleus accumbens at any dose tested $(0,3,10,30 \mathrm{nmol})$. The number of determinations is illustrated within the bar plots for each experiment. All animals received all treatments in each of these experiments. $C$, The AMPA receptor antagonist NBQX $(0.1 \mathrm{nmol})$ blocked motor activity elicited by DHPG $(5 \mathrm{nmol})$ microinjection into nucleus accumbens $\left(F_{(3,20)}=5.919 ; p=\right.$ 0.0046). The number of determinations is displayed in the bar, and each animal received all treatments in random order. $D$, The time course data reveal that AMPA receptor blockade with NBQX abolished DHPG-induced motor activity over the entire 2 hr test period. A two-way ANOVA with repeated measures over time shows a significant effect of treatment $\left(F_{(3,20)}=5.919 ; p=0.0046\right)$ and a near significant treatment $\times$ time interaction $\left(F_{(7,21)}=1.618\right.$; $p=0.0531$ ). Post hoc comparison using Fischer's PLSD reveals only a significant effect of DHPG alone when compared with vehicle controls. The number of determinations is shown in Vehicle of $A$. ${ }^{*} p<0.05$, compared with vehicle microinjection.

\section{DISCUSSION}

The present study demonstrates that repeated cocaine administration produces an enduring attenuation in the neurochemical and behavioral consequence of stimulating group I mGluRs in the nucleus accumbens. The capacity of the group I agonist DHPG to elevate extracellular glutamate levels and to stimulate motor activity was blunted. Furthermore, this blunting was associated with a cocaine-induced reduction in protein encoded by the Homer1 gene that is known to regulate mGluR1/5 signaling.

\section{Characterization of the pharmacological action of DHPG infusion into the nucleus accumbens}

The increase in extracellular glutamate produced by DHPG is consistent with previous reports showing that activation of mGluRs in cortical synaptosomes increases 4-aminopyridineinduced glutamate release (Herrero et al., 1992; Reid et al., 1999) and that DHPG elevates extracellular glutamate levels in parietal cortex (Moroni et al., 1998). The DHPG-mediated increase in extracellular glutamate levels can arise from either neuronal or glial stores, because both cell types possess group I mGluRs that when stimulated promote the efflux of glutamate (Chen et al., 1997; Bernstein et al., 1998). Glutamate release from glia and neurons can proceed via two distinct mechanisms: (1) increased vesicular release and (2) efflux of cytosolic glutamate through glutamate transporters or exchangers (Thomsen et al., 1994; Araque et al., 2000). The fact that blocking $\mathrm{N}$-type $\mathrm{Ca}^{2+}$ channels prevented DHPG-induced elevation in extracellular glutamate supports a mechanism involving vesicular release. Moreover, although glia possess $\mathrm{Ca}^{2+}$-dependent protein assemblies that mediate vesicular release, glial cytoplasmic $\mathrm{Ca}^{2+}$ arises primarily from intracellular $\mathrm{Ca}^{2+}$ stores and $\mathrm{L}$ - and T-type voltage-gated $\mathrm{Ca}^{2+}$ channels (Sontheimer, 1994; Araque et al., 


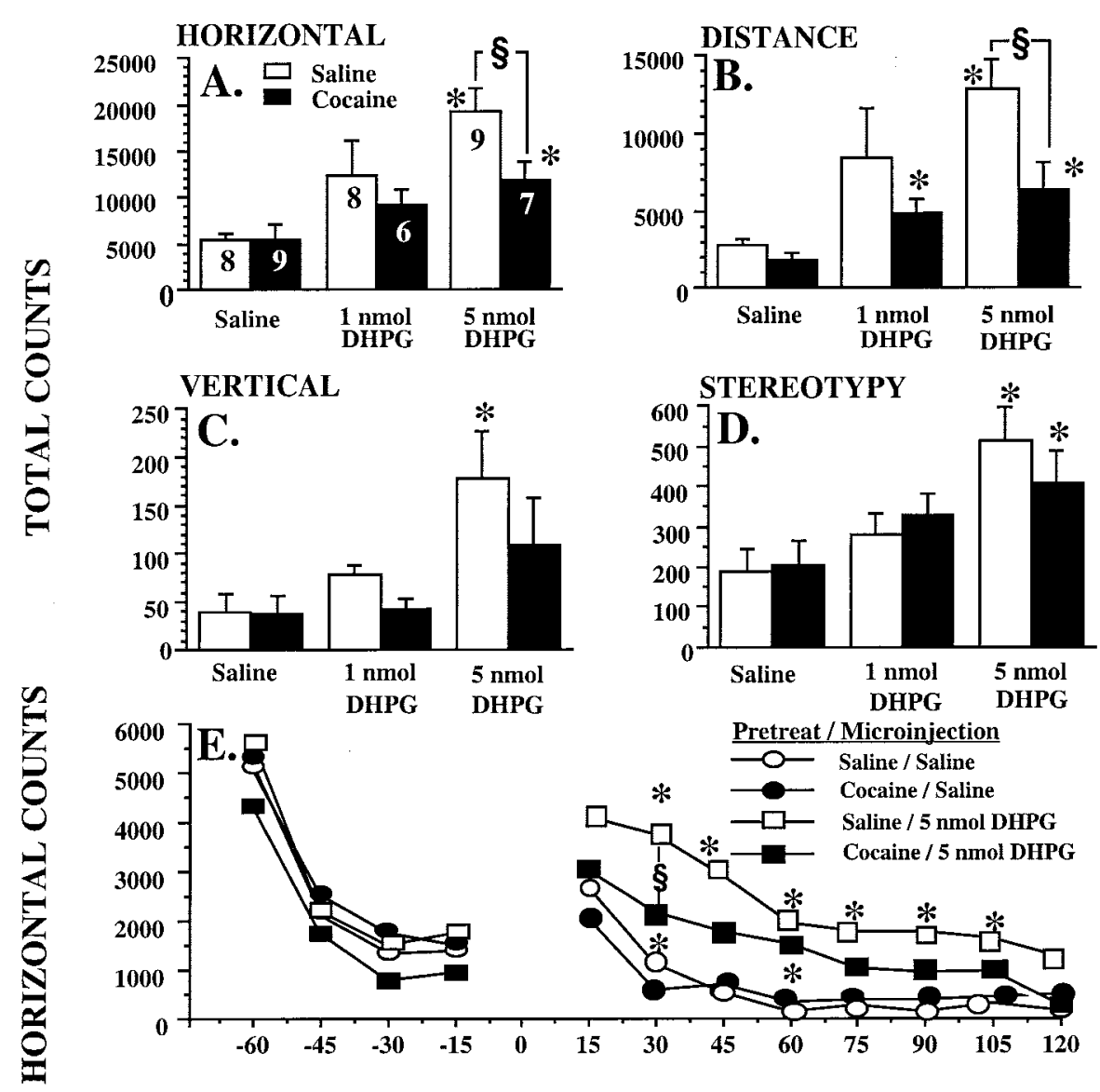

TIME (MINUTES)
Figure 4. DHPG-induced motor activity is blunted in animals administered repeated cocaine injections after a 3 week withdrawal period. Data are represented as mean \pm SEM total photocell counts during the $2 \mathrm{hr}$ test period after microinjection. $A$, Animals administered repeated cocaine display blunted horizontal motor activity compared with saline-treated controls at the behaviorally active dose of DHPG (5 nmol). An overall two-way ANOVA reveals a significant effect of saline or cocaine pretreatment $\left(F_{(1,41)}=4.212 ; p=0.0466\right)$, as well as a significant effect of dose of DHPG $\left(F_{(2,41)}=12.094 ; p=0.0001\right) . B$, Animals administered repeated cocaine also show a significant blunting in total distance traveled compared with saline-treated controls at the $5 \mathrm{nmol}$ dose of DHPG. A two-way ANOVA again reveals a significant effect of pretreatment $\left(F_{(1,41}=8.683 ; p=0.0001\right)$ and dose of DHPG $\left(F_{(2,41}=12.305 ; p=0.0053\right) . C$, Two-way analysis of vertical activity shows only a significant effect of dose of DHPG $\left(F_{(2,41}=4.201 ; p=\right.$ $0.0219)$. $D$, Animals administered repeated cocaine displayed no significant difference in estimated stereotyped behavior when compared with saline pretreated controls at any dose tested. A two-way ANOVA reveals a significant dose effect of DHPG $\left(F_{(1,41)}=12.37 ; p=\right.$ $0.0001)$ with no main effect of pretreatment. $E$, Time course data for horizontal activity reveals that cocaine-pretreated animals displayed a blunting in motor activation over the entire $2 \mathrm{hr}$ test period. A two-way ANOVA with repeated measures over time reveals a near significant pretreatment effect $\left(F_{(1,45)}=3.747 ; p=0.0592\right)$. There was no significant pretreatment $\times$ time interaction observed. The number of determinations for each dose is shown in $A .{ }^{*} p<0.05$, comparing DHPG with vehicle microinjected controls within the saline or cocaine pretreatment groups. ${ }^{\S} p<0.05$, comparing saline treatment with cocaine treatment within each dose of DHPG for total photocell counts $(A-C)$ or within each time point over the time course $(E)$.

A.

\begin{tabular}{lccc}
\hline Saline & mGluR 1a & mGluR 5 & Homer1bc \\
Cocaine & mGluR 1a & mGluR 5 & Homer1bc \\
B. & (12) $100 \pm 2.1$ & (12) $100 \pm 5.5$ \\
Saline & (12) $100 \pm 4.5$ & (16) $89 \pm \mathbf{4 . 2 *}$ & (17) $83 \pm \mathbf{3 . 3} *$ \\
Cocaine & (14) $92 \pm 8.3$ &
\end{tabular}

Figure 5. Three week withdrawal from repeated cocaine administration reduces mGluR5 and Homer $1 \mathrm{~b} / \mathrm{c}$ immunoreactivity in the medial nucleus accumbens. $A$, Representative Western blots of animals pretreated with repeated saline or cocaine demonstrating protein levels for mGluR1, mGluR5, and Homer 1b/c protein levels in medial nucleus accumbens after a 3 week withdrawal period. $B$, Densitometry measurements expressed as percentage of control \pm SEM. A one-way ANOVA reveals significant reductions in mGluR5 $\left(F_{(1,26)}=4.49 ; p=0.0438\right)$ and Homer1b/c $\left(F_{(1,27)}=7.755 ; p=0.0097\right)$ protein levels in cocaine-treated rats. The number of determinations is shown in parentheses. ${ }^{*} p<0.05$, ${ }^{* *} p<0.01$ comparing saline pretreatment with cocaine.

2000). Thus, inhibition by the selective $\mathrm{N}$-type $\mathrm{Ca}^{2+}$ channel antagonist $\omega$-conotoxin argues that DHPG-induced release is neuronal and not glial [but see Agrawal et al. (2000)]. Also consistent with neuronal origin, the inhibition of DHPG-induced elevation in extracellular glutamate by blocking voltagedependent $\mathrm{Na}^{+}$channels suggests that action potential generation is necessary. The involvement of action potentials in the elevation of extracellular glutamate by DHPG could indicate that the effect is not mediated by presynaptic terminals. However, the capacity of mGluR1 and mGluR5 to increase cytosolic $\mathrm{Ca}^{2+}$ via stimulating release from the endoplasmic reticulum or opening L-type $\mathrm{Ca}^{2+}$ channels indicates a presynaptic priming effect on vesicular release that would not necessarily be revealed by blocking action potential-induced activation of $\mathrm{N}$-type $\mathrm{Ca}^{2+}$ channels (Kammermeier et al., 2000; Schumacher et al., 2000). Demonstrating a priming action by mGluR1 and mGluR5, Cochilla and Alford (1998) found that although mGluR1 stimulation did not produce excitatory potentials, it potentiated the magnitude of electrically stimulated EPSPs in motor neurons. Taken together, these data indicate that the increase in extracellular glutamate by DHPG is largely of presynaptic neuronal origin, although some involvement of glial stores cannot be ruled out.

The group I mGluR agonist DHPG has equal affinity for mGluR1 and mGluR5 in vitro (Pin et al., 1999). However, coadministration with the selective mGluR1 antagonist AIDA but not the selective mGluR5 antagonist MPEP abolished DHPGinduced elevation in extracellular glutamate. This is consistent with the observation that motor activity elicited by the microinjection of DHPG into the nucleus accumbens is also blocked by 
Table 1. Withdrawal from repeated cocaine administration produced no significant changes in protein levels in any brain region shown

\begin{tabular}{|c|c|c|c|c|}
\hline \multirow[b]{2}{*}{ Brain region } & \multirow[b]{2}{*}{ Treatment } & \multirow[b]{2}{*}{ mGluR1a } & \multicolumn{2}{|c|}{ (n) $\%$ Control $\pm \mathrm{SEM}$} \\
\hline & & & mGluR5 & Homer1bc \\
\hline \multirow[t]{2}{*}{ Prefrontal cortex } & Saline & (11) $100 \pm 2.9$ & (11) $100 \pm 1.4$ & (12) $100 \pm 5.5$ \\
\hline & Cocaine & (17) $98 \pm 4.9$ & (16) $99 \pm 2.9$ & (16) $97 \pm 5.8$ \\
\hline \multirow[t]{2}{*}{ Lateral nucleus accumbens } & Saline & (9) $100 \pm 6.9$ & (9) $100 \pm 1.4$ & (9) $100 \pm 5.3$ \\
\hline & Cocaine & (12) $101 \pm 6.8$ & (12) $97 \pm 2.7$ & (12) $107 \pm 7.0$ \\
\hline \multirow[t]{2}{*}{ Striatum } & Saline & (12) $100 \pm 2.4$ & (12) $100 \pm 4.6$ & (12) $100 \pm 5.9$ \\
\hline & Cocaine & (16) $92 \pm 3.7$ & (16) $110 \pm 5.6$ & (16) $99 \pm 3.7$ \\
\hline \multirow[t]{2}{*}{ Ventral tegmental area } & Saline & (12) $100 \pm 6.7$ & (12) $100 \pm 6.2$ & (9) $100 \pm 2.1$ \\
\hline & Cocaine & (16) $100 \pm 5.3$ & (16) $102 \pm 5.2$ & (12) $96 \pm 6.5$ \\
\hline
\end{tabular}

Data are represented as the mean percentage change from control \pm SEM for all animals pooled according to pretreatment and listed by brain region tested.

the mGluR1-selective antagonist CPCCOEt (Swanson and Kalivas, 2000) but not by the selective mGluR5 antagonist MPEP (this study). The fact that the mGluR1 subtype is mediating both the neurochemical and behavioral effects of DHPG in the nucleus accumbens poses the possibility that DHPG-induced release of glutamate may mediate the motor stimulant response. Consistent with this hypothesis, the behavioral activation elicited by DHPG was abolished by antagonizing AMPA receptors, indicating that DHPG-induced release of glutamate may be stimulating postsynaptic AMPA receptors to elicit motor activation. Alternatively, mGluR1 and mGluR5 modulation of AMPA receptor-mediated postsynaptic potentials is well documented (O'Leary and O'Connor, 1997; Ugolini et al., 1997, 1999), and this could account for the inhibition of DHPG-induced motor activation by NBQX.

\section{Implications for cocaine effects on Homer1bc protein levels}

The Homer1 gene encodes Homer1b/c and a shortened Homer1a protein product that lacks a full $\mathrm{C}$-terminal region (Xiao et al., 1998). Homer1b/c is present at relatively high levels under basal conditions in the nucleus accumbens where it may contribute to a number of synaptic functions. For instance, Homer1b/c contains an amino-terminal EVH1 domain that mediates binding to mGluR1 and mGluR5 and $\mathrm{IP}_{3}$ receptors, and a helical coiled-coil region located on the $\mathrm{C}$ terminus that confers the ability of these proteins to form Homer multimers. It has been demonstrated that Homer1b/c multimers are able to functionally cross-link mGluRs and $\mathrm{IP}_{3}$ receptors and thereby facilitate the ability of mGluRmediated $\mathrm{IP}_{3}$ production to mobilize intracellular $\mathrm{Ca}^{2+}$ from internal stores ( $\mathrm{Tu}$ et al., 1998). In addition to modulating intracellular $\mathrm{Ca}^{2+}$ release, Homer1b/c binds to the intracellular scaffolding protein Shank (Tu et al., 1999). The Shank family of proteins interacts with guanylate kinase-associated protein, which can bind the PSD-95-NMDA (Naisbitt et al., 1999). Thus, Homer1b/c may serve to cluster the $\mathrm{mGluR}-\mathrm{IP}_{3}$ receptor complex with iGluRs, and this signaling complex may promote the ability of $\mathrm{Ca}^{2+}$ flux through NMDA receptors to further facilitate $\mathrm{Ca}^{2+}$ release from the endoplasmic reticulum.

The proposed scaffolding function of Homer is consistent with the contribution by decreased Homer $1 \mathrm{~b} / \mathrm{c}$ levels in cocaineinduced blunting of DHPG effects on extracellular glutamate and motor behavior. Although this hypothesis is not proven in the present report, it was found that Homer1b/c was altered by repeated cocaine only at 3 weeks after the last daily cocaine injection, and DHPG-induced elevation in extracellular glutamate was also affected only at this withdrawal time. In contrast, at $24 \mathrm{hr}$ after the last daily cocaine injection, neither the effect of
DHPG nor Homer1b/c levels in the medial accumbens were altered.

\section{Cocaine effects on group I mGluRs}

Given the pharmacological data showing primary involvement of mGluR1 in the behavioral and neurochemical action of DHPG, a role for the reduced levels of mGluR5 protein after withdrawal from repeated cocaine administration is not readily apparent. mGluR5 is primarily postsynaptic, and stimulating this subtype causes PKC-dependent phosphorylation of the GluR1 and GluR2 AMPA subunits (Roche et al., 1996; Ugolini et al., 1999). The mGluR-induced PKC phosphorylation of GluR2 parallels desensitization of AMPA receptors [Nakazawa et al. (1997), but see Anwyl (1999)]. Thus, it is conceivable that the previously reported sensitization of AMPA-induced behaviors produced by repeated cocaine administration (Bell and Kalivas, 1996; Pierce et al., 1996) may be, in part, a result of reduced levels of mGluR5.

The sensitization of AMPA-induced behaviors may also explain why DHPG-induced elevation in extracellular glutamate was nearly abolished in subjects pretreated with daily cocaine injections, whereas DHPG-induced behavior was only partly inhibited (compare Figs. 2 and 4). Because the motor stimulant response to DHPG is mediated by AMPA receptors (Fig. 3), the smaller DHPG-induced increases in extracellular glutamate would be better able to elicit motor activation in cocainepretreated animals where AMPA receptors have been functionally sensitized. Also contributing to the difference in cocaineinduced blunting of DHPG actions on extracellular glutamate and behavior is the fact that dialysis probes sample transmitter overflow from synaptic release sites and may therefore not detect behaviorally significant increases in synaptic release.

The fact that DHPG acts on mGluR1 to promote glutamate release indicates a presynaptic locus for mGluR1 receptors. The lack of effect by repeated cocaine treatment on mGluR1a protein levels suggests that the cocaine-induced blunting of the mGluRdependent elevation in extracellular glutamate does not arise from decreased overall levels of mGluR1a. As outlined above, a functional dysregulation of $\mathrm{mGluR} 1 \mathrm{a}$ receptors on glutamatergic terminals could arise from the cocaine-induced reduction in levels of Homer1b/c protein. Although mGluR1a is considered to be located primarily at postsynaptic sites, there is a recent demonstration for a presynaptic localization of these receptors on glutamatergic terminals (Awad et al., 2000). Also, substantial presynaptic localization of mGluR1b has been shown in the rat ventral striatum (Fotuhi et al., 1993). Although this localization indicates possible involvement of mGluR1b, the mGluR1b-d receptor variants lack the $\mathrm{C}$-terminal region (present in 

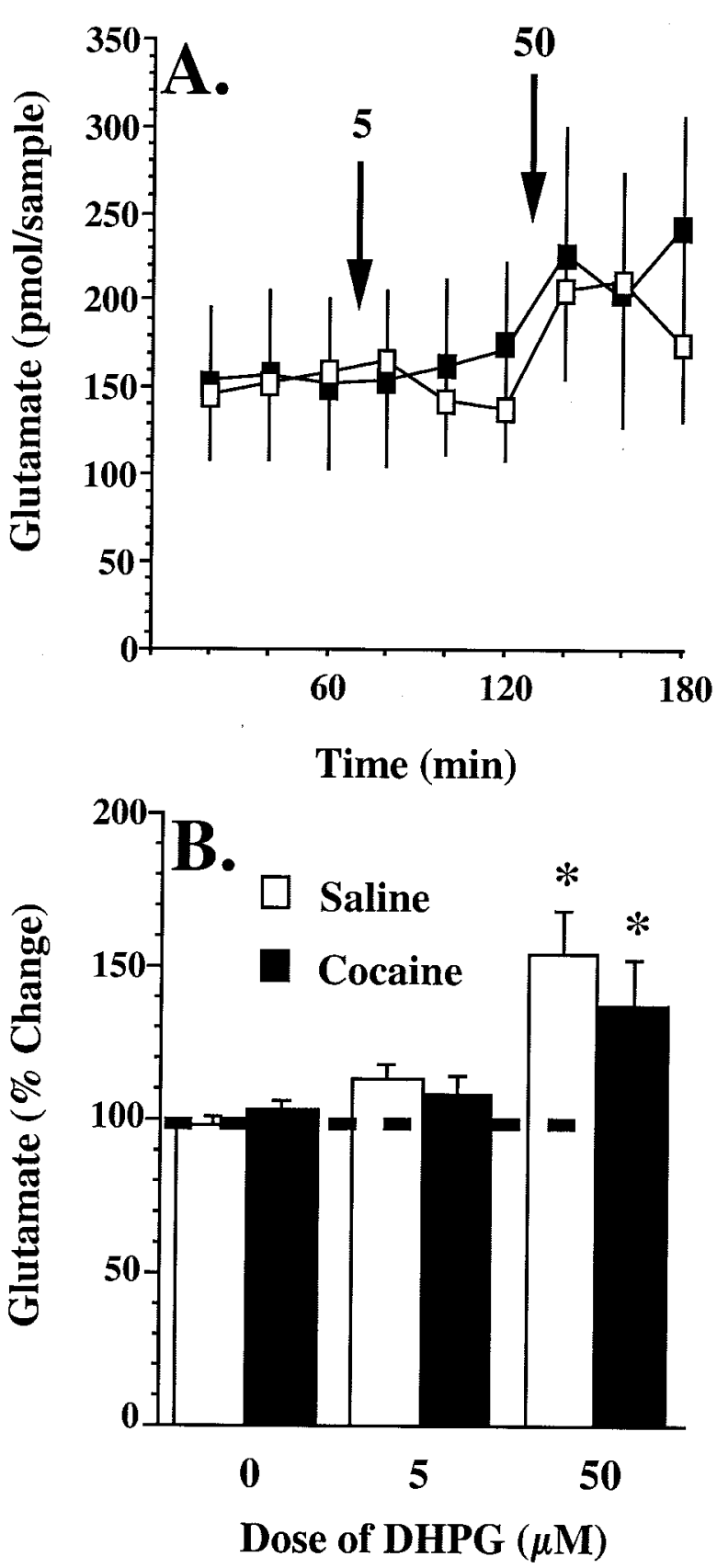

Figure 6. Repeated cocaine does not alter Homer1b/c, mGluR5 levels, or DHPG-induced increase in extracellular glutamate in the nucleus accumbens at $24 \mathrm{hr}$ after the last daily injection. $A$, Reverse dialysis of DHPG into the medial nucleus accumbens after a $24 \mathrm{hr}$ withdrawal period is not altered in cocaine animals when compared with saline-treated controls. Raw data are represented as picomoles per sample in $A$ and expressed as percentage of baseline glutamate levels \pm SEM in $B$. The percentage change data in $B$ represents the average of the last two samples collected at each dose of DHPG when compared with the average of the three baseline samples. The number of determinations in each pretreatment group was as follows: repeated saline $=9$; repeated cocaine $=8$. A two-way ANOVA with repeated measures over DHPG dose reveals no significant effect between cocaine and saline pretreatments, whereas a significant repeated measures effect of DHPG dose was observed $\left(F_{(2,30)}=6.305 ; p=0.0052\right)$. There was no significant pretreatment $\times$ dose of DHPG interaction. One-way ANOVA showed a near significant effect of dose in saline-pretreated animals $\left(F_{(2,26)}=0.1 .492 ; p=0.07\right)$ and a significant dose effect in cocaine-pretreated animals $\left(F_{(2,23)}=0.477 ; p=\right.$ $0.0383)$. Post hoc comparisons using Fischer's PLSD revealed a significant increase in extracellular glutamate levels at $50 \mu \mathrm{M}$ DHPG in both saline-
A.

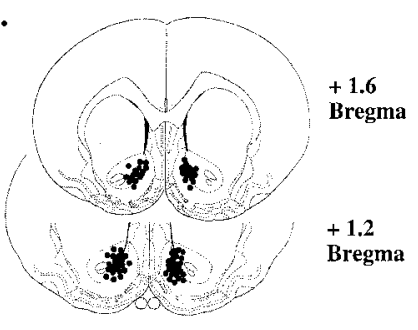

B.

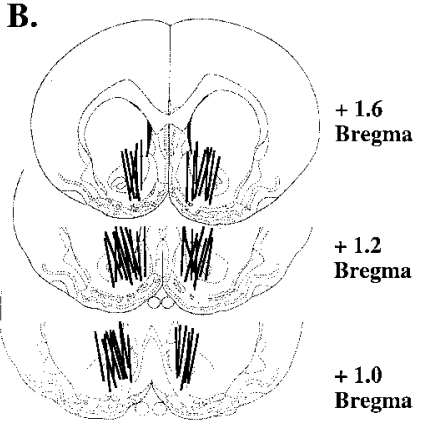

Figure 7. Location of the microinjection cannula tips in the nucleus accumbens for behavioral and microdialysis studies. The numbers indicate millimeters rostral to bregma according to the atlas of Paxinos and Watson (1986). A, Verification of microinjection placement for the behavioral experiments indicates that injections were placed within the medial nucleus accumbens, which includes both the shell and medial core subregions. $B$, Probe placements for the microdialysis experiments reveal that the probes traversed the shell and medial core regions of the nucleus accumbens.

mGluR1a) that is essential for interaction with Homer proteins (Brakeman et al., 1997)

\section{Homer1b/c, mGluRs, and addiction}

The present data demonstrate that repeated cocaine administration produces long-term attenuation of group I mGluR function in the nucleus accumbens and that this diminished function is associated with decreased levels of mGluR5 and Homer1b/c protein. The induction of behavioral sensitization by repeated cocaine administration is a model of psychostimulant-induced neuroplasticity (White and Kalivas, 1998). Consistent with a role for mGluRs, amphetamine-induced behavioral sensitization was shown to be blocked by the nonselective mGluR antagonist $(R S)$ $\alpha$-methyl-4-carboxyphenylglycine (Vezina et al., 1999). Moreover, AMPA receptor stimulation in the nucleus accumbens is a critical component for the expression of addiction-related behaviors, including cocaine-induced behavioral sensitization and the reinstatement of self-administration behavior (Pierce et al., 1996; Cornish and Kalivas, 2000). Given the capacity of group I mGluRs to stimulate glutamate release and cause functionally relevant AMPA receptor phosphorylation (Nakazawa et al., 1997), the neuroadaptations produced by repeated cocaine that are documented in this report may contribute to the role played by glutamate transmission in addiction.

\section{REFERENCES}

Agrawal SK, Nashmi R, Fehlings MG (2000) Role of L- and N-type calcium channels in the pathophysiology of traumatic spinal cord white matter injury. Neuroscience 99:179-188.

Anwyl R (1999) Metabotropic glutamate receptors: electrophysiological properties and role in plasticity. Brain Res 29:83-120.

Araque A, Nianzhen L, Doyle RT, Haydon PG (2000) SNARE protein-dependent glutamate release from astrocytes. J Neurosci 20:666-673.

Awad H, Hubert GW, Smith Y, Levey AI, Conn JP (2000) Activation of metabotropic glutamate receptor 5 has direct excitatory effects and

$\leftarrow$

and cocaine-pretreated groups when compared with baseline levels. $C$, Medial nucleus accumbens protein levels for mGluR5 and Homer1b/c were not significantly changed in animals withdrawn for $24 \mathrm{hr}$ from repeated cocaine administration. The number of determinations for each group is shown in parentheses. ${ }^{*} p<0.05$, comparing saline or cocaine pretreatment within each dose of DHPG tested with their respective baseline glutamate levels. 
potentiates NMDA receptor currents in neurons of the subthalamic nucleus. J Neurosci 20:7871-7879.

Bell K, Kalivas PW (1996) Context-specific cross sensitization between systemic cocaine and intra-accumbens AMPA infusion in rats. Psychopharmacology 127:377-383.

Berke J, Hyman S (2000) Addiction, dopamine, and the molecular mechanisms of memory. Neuron 25:515-532.

Bernstein M, Behnisch T, Balschun D, Reymann KG, Reiser G (1998) Pharmacological characterisation of metabotropic glutamatergic and purinergic receptors linked to $\mathrm{Ca}^{2+}$ signalling in hippocampal astrocytes. Neuropharmacology 37:169-178.

Brakeman PR, Lanahan AA, O'Brien R, Roche K, Barnes CA, Huganir RL, Worley PF (1997) Homer: a protein that selectively binds metabotropic glutamate receptors. Nature 386:221-223.

Cadoni C, Di Chiara G (1999) Reciprocal changes in dopamine responsiveness in the nucleus accumbens shell and core and in the dorsal caudate-putamen in rats sensitized to morphine. Neuroscience 90:447-455

Chen J, Backus KH, Deitmer JW (1997) Intracellular calcium transients and potassium current oscillations evoked by glutamate in cultured rat astrocytes. J Neurosci 17:7278-7287.

Cochilla A, Alford S (1998) Metabotropic glutamate receptor-mediated control of neurotransmitter release. Neuron 20:1007-1016.

Conn PJ, Pin J-P (1997) Pharmacology and functions of metabotropic glutamate receptors. Annu Rev Pharmacol Toxicol 37:205-237.

Cornish J, Kalivas P (2000) Glutamate transmission in the nucleus accumbens mediates relapse in cocaine addiction. $\mathrm{J}$ Neurosci 20:RC89(1-5).

Fallon JH, Moore RY (1978) Catecholamine innervation of basal forebrain. IV. Topography of the dopamine projection to the basal forebrain and striatum. J Comp Neurol 180:545-580.

Fotuhi, M, Sharp AH, Glatt CE, Hwant PM, von Krosigk M, Snyder SH, Dawson TM (1993) Differential localization of phosphoinositide-linked metabotropic glutamate receptor (mGluR1) and the inositol 1,4,5-trisphosphate receptor in rat brain. $J$ Neurosci 13:2001-2012.

Heidbreder CA, Thompson AC, Shippenberg TS (1996) Role of extracellular dopamine in the initiation and long-term expression of behavioral sensitization to cocaine. J Pharmacol Exp Ther 278:490-502.

Heimer L, Zahm DS, Churchill L, Kalivas PW, Wohltmann C (1991) Specificity in the projection patterns of accumbal core and shell in the rat. Neuroscience 41:89-125.

Herrero I, Miras-Portugal MT, Sanchez-Prieto J (1992) Positive feedback of glutamate exocytosis by metabotropic presynaptic receptor stimulation. Nature 360:163-166.

Kalivas PW, Duffy P (1993) Time course of extracellular dopamine and behavioral sensitization to cocaine. I. Dopamine axon terminals. J Neurosci 13:266-275.

Kalivas PW, Duffy P, DuMars LA, Skinner C (1988) Behavioral and neurochemical effects of acute and daily cocaine. J Pharmacol Exp Ther 245:485-492.

Kammermeier PJ, Xiao B, Tu JC, Worley PF, Ikeda SR (2000) Homer proteins regulate coupling of group I metabotropic glutamate receptors to N-type calcium and T-type potassium channels. J Neurosci 20:7238-7245.

Kato A, Ozawa F, Saitoh Y, Fukazawa Y, Sugiyama H, Inoduchi K (1998) Novel members of the Visl/Homer family of PDZ proteins that bind metabotropic glutamate receptors. J Biol Chem 273:23969-23975.

Kim J-H, Vezina P (1998) Metabotropic glutamate receptors in the rat nucleus accumbens contribute to amphetamine-induced locomotion. J Pharmacol Exp Ther 284:317-322.

Meredith GE, Pennartz CMA, Groenewegen HJ (1993) The cellular framework for chemical signalling in the nucleus accumbens. Prog Brain Res 99:3-24.

Moghaddam B (1993) Stress preferentially increases extraneuronal levels of excitatory amino acids in the prefrontal cortex: comparison to hippocampus and basal ganglia. J Neurochem 60:1650-1657.

Moroni F, Cozzi A, Lombardi G, Sourtcheva S, Leonardi P, Carfi M, Pellicciari R (1998) Presynaptic mGlu1 type receptors potentiate transmitter output in the rat cortex. Eur J Pharmacol 347:189-195.

Naisbitt S, Kim E, Tu JC, Xiao B, Sala C, Valtschanoff J, Weinberg RJ, Worley PF, Sheng M (1999) Shank, a novel family of postsynaptic density proteins that binds to the NMDA receptor/PSD-95/GKAP complex and contactin. Neuron 23:569-582.

Nakazawa K, Mikawa S, Ito M (1997) Persistent phosphorylation paral- lels long-term desensitization of cerebellar Purkinje cell AMPA-type glutamate receptors. Learn Mem 3:578-591.

Nestler EJ (2001) Molecular basis of long-term plasticity underlying addiction. Nat Rev Neurosci 2:119-128.

O'Leary D, O'Connor J (1997) Potentiation of synaptic transmission in the rat dentate gyrus in vitro by $(S)$-3,5-dihydroxyphenylglycine $((S)$ DHPG). Neurosci Lett 229:29-32.

Ottersen O, Landsend A (1997) Organization of glutamate receptors at the synapse. Eur J Neurosci 9:2219-2224.

Paulson PE, Robinson TE (1995) Amphetamine-induced timedependent sensitization of dopamine neurotransmission in the dorsal and ventral striatum: a microdialysis study in behaving rats. Synapse 19:56-65.

Paxinos G, Watson C (1986) A stereotaxic atlas of the brain. New York: Academic.

Pierce RC, Bell K, Duffy P, Kalivas PW (1996) Repeated cocaine augments excitatory amino acid transmission in the nucleus accumbens only in rats having developed behavioral sensitization. $\mathbf{J}$ Neurosci 16:1550-1560.

Pierce RC, Kalivas PW (1997) Repeated cocaine modifies the mechanism by which amphetamine releases dopamine. $J$ Neurosci 17:3254-3261.

Pin J, Colle C, Bessis A, Acher F (1999) New perspectives for the development of selective metabotropic glutamate receptor ligands. Eur J Pharmacol 375:277-294

Reid M, Toms N, Bedingfield J, Roberts P (1999) Group I mGlu receptors potentiate synaptosomal $\left[{ }^{3} \mathrm{H}\right]$ glutamate release independently of exogenously applied arachidonic acid. Neuropharmacology 38:477-485.

Roche KW, O’Brien RJ, Mammen AL, Bernhardt J, Huganir RL (1996) Characterization of multiple phosphorylation sites on the AMPA receptor GluR1 subunit. Neuron 16:1179-1188.

Romano C, Sesma MA, McDonald CT, O’Malley K, Van Den Pol AN, Olney JW (1995) Distribution of metabotropic glutamate receptor mGluR5 immunoreactivity in rat brain. J Comp Neurol 355:455-469.

Schumacher TB, Steffens R, Blumcke I, Schramm J, Elger CE, Steinhauser C (2000) Modulation of calcium channels by group I and group II metabotropic glutamate receptors in dentate gyrus neurons from patients with temporal lobe epilepsy. Epilepsia 41:1249-1258.

Sontheimer H (1994) Votage-dependent ion channels in glial cells. Glia 11:156-172.

Swanson CJ, Kalivas PW (2000) Regulation of locomotor activity by metabotropic glutamate receptors in the nucleus accumbens and ventral tegmental area. J Pharmacol Exp Ther 292:406-414.

Thomsen C, Hansen L, Suzdak PD (1994) L-glutamate uptake inhibitors may stimulate phosphoinositide hydrolysis in baby hamster kidney cells expressing mGluR1a via heteroexchange with L-glutamate without direct activation of mGluR1a. J Neurochem 63:2038-2047.

Timmerman W, Westerink BH (1997) Brain microdialysis of GABA and glutamate: what does it signify? Synapse 27:242-261.

Tu JC, Xiao B, Yuan JP, Lanahan AA, Leoffert K, Li M, Linden DJ, Worley PF (1998) Homer binds a novel proline-rich motif and links group 1 metabotropic glutamate receptors with IP3 receptors. Neuron 21:717-726.

Tu JC, Xiao B, Naisbitt S, Yuan JP, Petralia RS, Brakeman P, Doan A, Vinay KA, Lanahan AA, Sheng M, Worley PF (1999) Coupling of mGluR/Homer and PSD-95 complexes by the Shank family of postsynaptic proteins. Neuron 23:583-592.

Ugolini A, Corsi M, Bordi F (1997) Potentiation of NMDA and AMPA responses by group I mGluR in spinal cord motoneurons. Neuropharmacology 36:1047-1055.

Ugolini A, Corsi M, Bordi F (1999) Potentiation of NMDA and AMPA responses by the specific mGluR5 agonist CHPG in spinal cord motoneurons. Neuropharmacology 38:1569-1576.

Vezina P, Pierre PJ, Lorrain DS (1999) The effect of previous exposure to amphetamine on drug-induced locomotion and self-administration of a low dose of the drug. Psychopharmacology 147:125-134.

White FJ, Kalivas PW (1998) Neuroadaptations involved in amphetamine and cocaine addiction. Drug Alcohol Depend 51:141-154.

Wolf ME (1998) The role of excitatory amino acids in behavioral sensitization to psychomotor stimulants. Prog Neurobiol 54:679-720.

Xiao, B, Tu, JC, Petralia RS, Yuan JP, Doan, A, Breder CD, Ruggiero, A, Lanahan AA, Wenthold RJ, Worley PF (1998) Homer regulates the association of Group 1 metabotropic glutamate receptors with multivalent complexes of homer-related, synaptic proteins. Neuron 21:707-716. 